Shock, Publish Ahead of Print

DOI : $10.1097 /$ SHK.0000000000000917

\title{
Neuroprotection with the p53-Inhibitor Pifithrin- $\mu$ after Cardiac Arrest in a Rodent
}

\section{Model}

Michael Glas ${ }^{1}$; Tamara Frick ${ }^{1}$; Dirk Springe ${ }^{1}$; Alessandro Putzu ${ }^{1}$; Patrick Zuercher ${ }^{1}$; Denis

Grandgirard $^{2}$; Stephen L. Leib ${ }^{2}$; Stephan M. Jakob ${ }^{1}$; Jukka Takala ${ }^{1}$; Matthias Haenggi ${ }^{1}$

1 Department of Intensive Care Medicine, Inselspital, Bern University Hospital, University of

Bern, CH-3010 Bern, Switzerland

2 Neuroinfection Laboratory, Institute for Infectious Diseases, University of Bern, CH-3010

Bern, Switzerland

\section{Corresponding author:}

Matthias Haenggi, MD

Department of Intensive Care Medicine

Inselspital, University Hospital Bern

CH-3010 Bern, Switzerland

phone: +41-31-632 4144

fax: +41-31-632 4100

e-mail: matthias.haenggi@insel.ch 


\section{Funding}

The study was financially supported in parts from the „Stiftung für die Forschung in Anästhesiologie und Intensivmedizin, Bern“. The Department of Intensive Care Medicine of the Inselspital (Bern University Hospital, University of Bern) funded the study. DG and SL receive support from the Swiss National Science Foundation (31003A-138094). The funding agencies had no role in design, in the collection, analysis, and interpretation of data; writing the manuscript; and in the decision to submit the manuscript.

\section{Running Head}

Effect of Pifithrin on rat brains in cardiac arrest 


\section{Abstract}

Background: The small molecule pifithrin- $\mu$ reversibility inhibits the mitochondrial pathway of apoptosis. The neuronal effects of pifithrin- $\mu$ applied after cardiac arrest are unknown. We hypothesized that pifithrin- $\mu$ reduces neuronal damage in the most vulnerable brain region, the hippocampus, after cardiac arrest.

Methods: In two randomized controlled series we administered pifithrin- $\mu$ or control in 109 rats resuscitated after 8 or 10 minutes of cardiac arrest. Neuronal damage was blindly assessed with histology (Fluoro Jade B: FJB, cresyl violet: CV) in the most vulnerable brain region (CA1 segment of hippocampus) and with a series of neurobehavioral tests (Open Field Task, Tape-Removal Test, Morris Water Maze test). Mixed ANOVA was used to combine both series, simple comparisons were done with t-tests or Mann-Whitney U test.

Results: Pifithrin- $\mu$ reduced the number of degenerating, FJB-positive neurons by $25 \%$ (mixed ANOVA p group $=0.014)$. This was more prominent after 8 minutes cardiac arrest $(8$ minutes arrest pifithrin- $\mu 94 \pm 47$ vs control $128 \pm 37$; $n=11$ each; 10 minutes arrest pifithrin$\mu 78 \pm 44, \mathrm{n}=15$ vs control $101 \pm 31, \mathrm{n}=18 ; \mathrm{p}$ group* arrest length interaction $=0.622$ ). The reduction of ischemic $\mathrm{CV}$-positive neurons in pifithrin- $\mu$ animals was not significant $($ ANOVA p group $=0.063)$. No significant group differences were found in neurobehavioral testing.

Conclusion: Temporarily inhibition of apoptosis with pifithrin- $\mu$ after cardiac arrest decreases the number of injured neurons in the CA1 segment of hippocampus in a cardiac arrest rat model, without clinical correlate. Further studies should elucidate the role of this neuroprotective agent in different settings and with longer cardiac arrest. 
Key Words: Cardiac arrest; Rats; Apoptosis; Hypoxia-Ischemia, Brain; Cardiopulmonary Resuscitation; pifithrin- $\mu$ (=2-phenylacetylenesulfonamide); Neuroprotection 


\section{Introduction}

Cardiac arrest affects more than 300000 persons annually alone in the United States $(1,2)$ and is the most important cause of global cerebral ischemia. Only a minority of resuscitated patients is discharged in good neurological condition $(3,4)$. Global cerebral ischemia does not necessarily lead to immediate neuronal death, but initiates the apoptotic cascade, which results in neurodegeneration (5). This late neuronal degeneration may open a window of opportunity to mitigate the devastating effects of ischemia on the brain.

Delayed cell death and apoptosis following stress is directed by the tumor-suppressor geneproduct p53 $(6,7)$. Transgenic mice with definitive suppression of p53 ultimately develop cancer, but suppression of p53 might have short term advantages. Some studies have found promising effects, e.g. mice with reduced p53 activity survive otherwise lethal irradiation (8). Inhibition of $\mathrm{p} 53$ restores spontaneous locomotion of the animals after experimental stroke (9), protects neonatal rat brain from hypoxic-ischemic injury (10) and attenuate autophagic and apoptotic cell death in the cortex and hippocampus when given before cardiac arrest in rats (11).

The effect of blocking the p53 pathway after global ischemic-reperfusion injury induced by cardiac arrest is unknown. We assessed the feasibility and effect of a single dose of the antiapoptotic small molecule pifithrin- $\mu$ given after cardiac arrest of either 8 or 10 minutes. We hypothesized that pifithrin- $\mu$ reduces the numbers of degenerated cells in the most vulnerable part of the brain, the hippocampus Cornu Ammonis 1 (CA-1) segment, and improves outcome measured with neurobehavioral testing. 


\section{Material and Methods}

The study included two series: 1. randomized open label allocation of pifithrin (PIF) or placebo (C) following return of spontaneous circulation (ROSC) after 8 minutes of cardiac arrest $(\mathrm{n}=74)$ and evaluation of brain histology by a blinded assessor and neurobehavioral testing on day $1(n=23)$ or $5(n=22)$ or neurobehavioral testing with a Moris Water Maze starting at day 10-14 $(\mathrm{n}=23)$. Additional 6 rats were used as controls for brain histology (figure 1). 2. Randomized blinded allocation of PIF or C following ROSC after 10 minutes of cardiac arrest $(n=40)$, and brain histology and neurobehavioral testing on day 5 (figure 2a).The rational for the stepwise approach was to limit the number of used animals and to implement possible variations of the protocol (e.g. duration of cardiac arrest).

All animal studies were approved by the Animal Care and Experimentation Committee of the Canton of Bern, Switzerland (BE 55/13 and BE 16/15) and followed the Swiss national guidelines for the performance of animal experiments. Adult male Wistar rats (9-10 weeks old, Janvier Labs, Le Genest-Saint-Isle, France) were housed at the central animal facilities of the University of Bern with a $12 / 12 \mathrm{~h}$ light/dark cycle at $22^{\circ} \mathrm{C}$ and food and water ad libitum.

Randomization was done using concealed lots (sealed envelopes), in series 1. before anesthesia and in series 2. after return of spontaneous circulation. In case of failure of ROSC in series 1., the experiment was repeated immediately. Anesthesia, instrumentation, cardiac arrest/resuscitation, and postoperative care were standardized (12) and summarized in the Supplemental Digital Content, http://links.lww.com/SHK/A595. Briefly, after anesthesia induction, an endotracheal tube and arterial and venous catheters were inserted. Temperature was managed using an adjustable temperature plate for cooling/heating, and an infrared bulb. Cardiac arrest was induced with iv-injection of potassium and esmolol $(0.125 \mathrm{mmol}$ 
potassium and $9.375 \mathrm{mg}$ esmolol per animal (corresponding to $0.363 \mathrm{mmol} / \mathrm{kg}$ body weight potassium and $27.3 \mathrm{mg} / \mathrm{kg}$ body weight esmolol). Resuscitation was performed 8 minutes (series 1.) or 10 minutes (series 2.) later with ventilation with $100 \%$ oxygen, cardiac massage by 2 fingers at a metronome-guided frequency of $220^{-m i n}$, and administration of epinephrine and calcium. 5 minutes after ROSC, the study medication in series 1 . was given intraperitoneally [pifithrin- $\mu$ (Selleck Chemicals, via LuBioScience, Lucerne, Switzerland, substance for non-human use only) dissolved in $4 \%$ dimethylsulfoxide (DMSO) in phosphate buffered saline (vehicle) to a final concentration of $0.8 \mathrm{~g} / \mathrm{l}$; dose $8 \mathrm{mg}$ pifithrin- $\mu$ per $\mathrm{kg}$ ]. In series 2., a precision syringe driver infused the study medication or matching vehicle at a rate of $1 \mathrm{ml} / \mathrm{h}$ for 4 hours [pifithrin- $\mu$ dissolved in $96 \%$ ethanol $(10 \mathrm{mg} / \mathrm{ml}$, vehicle $)$ and after randomization further diluted in Ringer's solution (12 mg pifithrin- $\mu$ per $\mathrm{kg}$ containing $1.2 \mathrm{ml}$ ethanol $96 \%$ diluted to $4 \mathrm{ml}]$. The animals were euthanized according to the group allocation at day 1,5 or after day $10-14$ with $150 \mathrm{mg} / \mathrm{kg}$ pentobarbital intraperitoneally. For brain histology, $150 \mathrm{ml}$ iced normal saline was infused transcardially via the left ventricle before brain removal. The brain was post-fixed in buffered formalin ( $4 \%$ in phosphate buffered saline (PBS)) for 24 hours at $4{ }^{\circ} \mathrm{C}$ and then transferred to a $18 \%$ sucrose solution in PBS at $4^{\circ} \mathrm{C}$ until further processing.

Cryo-sections were obtained by cutting the brain in 10 and $45 \mu \mathrm{m}$ thick coronal sections using a Leica CM 1850 cryostat, after snap freezing of the tissue in methylbutane pre-cooled at $-80{ }^{\circ} \mathrm{C}$.

Fluoro-Jade B (FJB) staining was performed to assess the extent of neuronal damage on representative slides of the CA1 segment, the only structure with consistent damage after resuscitation from cardiac arrest (13). Fluorescence pictures of the hippocampus were recorded with a Zeiss fluorescence microscope (Axiolmager M4, Zeiss, Germany) equipped with a digital camera (Axiocam HRC) at a 100-fold magnification with mosaic reconstruction 
of individual captures using AxioVision software. The software Image J (Rasband, W.S., ImageJ, U. S. National Institutes of Health, Bethesda, Maryland, USA, http://imagej.nih.gov/ij/, 1997-2011) was used to determine the length (in mm) of the CA1 structure under investigation and to count all FJB + cells in this structure. Fluoro-Jade results were therefore expressed by normalizing the total amount of positive cells by the length of the investigated CA1.

The slices were also stained for Nissl substance with cresyl violet (CV). The percentage of cells with signs of ischemic damage (shrunken appearance and condensed nucleus) was estimated in the CA1 region by visual observation under a bright-field microscope of three slides representing the dorsal (septal) part of the hippocampus.

The histopathology was assessed in both series by the same expert (DG), who was blinded to the treatment and clinical data. In series 1 . only the histopathologic examiner was blinded, whereas in series 2 . the whole research team was blinded to treatment allocation.

We assessed general health (including death) daily until the end of the experiment, and weight and neurological function daily from baseline (pre-arrest) until day 5 with an established wide-ranging neuroscore (NDS) (14). Further neurobehavioral tests performed was an Open Field Task (15), the Tape-Removal Test (16) in the series 1. and a standard Morris Water Maze test (17) performed after wound healing (starting day 10 to day 14) in the series 1. Details of the tests are described in the ESM.

The data was tested for normality with the Shapiro-Wilk-Test, normal data were presented as mean $\pm \mathrm{SD}$, non-normal as medians and interquartile ranges [IQR]. Repeated assessments were compared in each experiment separately with a mixed ANOVA in normally distributed data with post-hoc tests corrected with Bonferroni's method. Non-normal data distribution precluded ANOVA, so we compared baseline measurements with the Mann-Whitney U test 
and the development within each group with the Friedman's test. All non-parametric tests are indicated in Italics. Simple comparisons were performed using parametric (t-test) or nonparametric statistics (Mann-Whitney U test) accordingly. Kaplan-Meier Survival Analysis (Log-Rank Test) was performed on series 2. only since there was only one animal which died after ROSC and treatment in the first series.

Results of pathologic-anatomic examinations of both series were combined with a 2-way ANOVA (factor 1: group [pifithrin or control], factor 2: experiment [nr 1:8 min cardiac arrest or 2: 10 min cardiac arrest]). This 2-way ANOVA was done once with the absolute cell count (numbers of damaged neurons), and once where the cell count of the damaged neurons in the PIF group was normalized to the respective cell count of the $\mathrm{C}$ group (x100\%). A $p<0.05$ was considered as significant. Calculations were performed using SigmaPlot/SigmaStat 12.3 (Systat Software GmbH, Erkrath, Germany).

\section{Results}

In experiment 1., 69 of the 74 randomized animals could be successfully resuscitated (93\%). One rat from the pifithrin group died on day 2 (details see figure 1). In experiment 2, 40 of the 42 animals could be resuscitated (95\%). Six animals died within one day (group PIF $n=2$; group $\mathrm{C} \mathrm{n}=4$ ) and one control animal was euthanatized on day 3 because of failure to thrive and weight loss (Group PIF ys C Kaplan-Meier Survival Analysis (Log Rank Test) p=0.22). Altogether, 51 rats treated with pifithrin- $\mu$ and 50 control animals could be analyzed.

Baseline characteristics of all animals in terms of temperature, hemodynamic and respiratory parameters as well as glucose and lactate variables did not differ between groups (see Supplemental Digital Content tables suppl 1a $+1 \mathrm{~b}$ and suppl 2, http://links.lww.com/SHK/A595). Time from start of resuscitation to ROSC did not 
significantly differ between the groups (8 min cardiac arrest: PIF 86 sec [73 - 100], C $76 \mathrm{sec}$ [71 - 95], $\mathrm{p}=0.40 ; 10 \min$ cardiac arrest: PIF $55 \sec [46-64]$, C $59 \sec [45-65], \mathrm{p}=0.61)$. Doses of adrenaline and calcium did not differ between groups (details see Supplemental Digital Content tables suppl 3, http://links.lww.com/SHK/A595), but adrenaline dose was significantly lower in the Series 2 because of the shorter time to ROSC.

There were no differences between groups in the trends of temperature, parameters of the aBGA (pH, pO2, pCO2), lactate and glucose (details see Supplemental Digital Content tables suppl $1 \mathrm{a}+1 \mathrm{~b}$ and suppl. 2 , http://links.lww.com/SHK/A595), even though the animals developed a significant lactic acidosis after cardiac arrest with consecutive changes in $\mathrm{pH}$. The same is true for hemodynamic parameters, where only changes over time were noted, but no differences between groups.

Pathologic-anatomic examination with FJB staining at day 5 showed a reduction of damaged neurons in both series 1. ( 8 min cardiac arrest, PIF: $94 \pm 46.9$ vs C: $128 \pm 36.6, p=0.084)$ and series 2. (10 min cardiac arrest, PIF: $78 \pm 43.7$ vs C: $101 \pm 31.0, p=0.095)$. These results demonstrated a robust and significant reduction of neuronal damage by $25 \%$, (2-way ANOVA of absolute cell count, group: $p=0.014$, experiment: $p=0.064$, no interaction; 2 -way ANOVA of cell count normalized to $100 \%$, group: $\mathrm{p}=0.019$, experiment: $\mathrm{p}=0.850$, no interaction), see table 1 and figure 3. In the CV staining, results followed the same trend, but did not reach significance, see table 2 .

In series 1., the histologic examinations performed on animals at Day 1 demonstrated only very few damaged neurons, the numbers were too low to perform statistics on them (see Supplemental Digital Content table suppl. 4, http://inks.lww.com/SHK/A595). The sectional CA1 area decreased between Day 1 and Day 5 in all animals (PIF $p=0.011, \mathrm{C} p<0.001$ ), with significant reduced shrinking of the CA1 cell layer as an indirect marker of reduced neuronal 
damage in the Pifithrin- $\mu$ group (mixed ANOVA, p group: 0.425, $\mathrm{p}$ time: $<0.001, \mathrm{p}$ for interaction: $<0.001$, details see table suppl. 5, http://links.lww.com/SHK/A595). The 3 nonischemic sham animals, euthanatized at day 5 , did not depict any signs of neuronal damage (table suppl. 6, http://links.lww.com/SHK/A595).

On the part of the general health and other neurobehavioral tests, no significant differences were observed in weight evolution, where all animals regained and surpassed their baseline weight. The Neuro Deficit Score was not sensitive enough to detect a difference compared to baseline beyond Day 2 in both groups. In the Tape Removal Test both groups returned to baseline levels after 5 days. In the open field the pifithrin-treated rats tended to be more mobile and to move longer distances, but without a significant difference (details see table suppl $7 \mathrm{a}+\mathrm{b}$, http://links.lww.com/SHK/A595). The Morris Water Maze Tests (table supple 7a, http://links.lww.com/SHK/A595) demonstrates a better learning capacity in the mean proximity to virtual platform (p group: $0.436, \mathrm{p}$ time: $<0.001$, $\mathrm{p}$ group $\mathrm{x}$ time: 0.016 ), the other parameters (time to first crossing and time in platform quadrant) are not significantly different.

\section{Discussion}

The main finding of our study is that after cardiac arrest temporary inhibition of the p53 mediated mitochondrial pathway of apoptosis with pifithrin- $\mu$ decreases neuronal damage in the most vulnerable structure of the brain, the hippocampus CA1 segment, by $25 \%$.

The p53 protein and its products have a central role in apoptosis (18). In unstressed cells, p53 remains at low cytoplasmatic concentrations. Following different stressors, p53 is upregulated and exerts pro-apoptotic activity via transcription of Bcl-2-family proteins in the 
nucleus (19), and through a mitochondrial pathway $(6,20)$. Dysfunctional p53 can be found in a wide range of cancer cells (21), but p53 is also involved in delayed cell death after traumatic brain injury (22), stroke (20), and contributes to side effects of anti-cancer drugs and irradiation. Inhibition of p53 by either drugs or gene knockout leads to improved survival after irradiation $(8,23)$, anti-cancer treatment $(10,24)$, neuronal ischemia $(9,10,20,25)$, myocardial ischemia (26) and oxidative stress in hepatoma cell lines (27). The small molecule pifithrin- $\alpha$ inhibits the transcription-dependent $\mathrm{p} 53$, whereas pifithrin- $\mu$ suppresses the $\mathrm{p} 53$ binding to the mitochondrial membrane (27). Targeting the mitochondrial pathway of p53 with pifithrin- $\mu$ compared to inhibition of transcription with pifithrin- $\alpha$ increases neuronal protection (10). In this experiment, Nijboer and colleagues demonstrated efficacy of pifithrin- $\mu$ in a neonatal unilateral ischemia and hypoxia rat model (10) with small group sizes $(\mathrm{n}<10)$. In their experiment, inhibition of apoptosis was accounted for the effect. Recently Ciu and colleagues confirmed the apoptotic (and autophagic) pathways and their subsequent inhibition with pifithrin- $\alpha$ in a asphyxial cardiac arrest model (11). In these experiments the rats were given pifithrin intracisternally before cardiac arrest, a model which differs in many aspects from ours. In our experiment we cannot prove the reduction of neuronal injury is caused by less apoptosis since we have not used a specific apoptosis staining (e.g. caspase 3 or TUNEL). Given the absence of injury on day one, and in similar experiments on day 2 (28), we assume that the observed degeneration on day 5 is due to the activation of the intrinsic apoptotic pathway.

Damage of the dorso-septal pole of the hippocampus in rats results in impaired spatial learning and memory. Unfortunately we could not detect group differences in the neurobehavioral tests. Our functional tests revealed important, albeit not sustained, functional impairment after cardiac arrest. E.g. the time to remove the tapes in the Tape Removal Test returned to baseline at Day 5 in both groups (see Supplemental Digital Content, table suppl. 
7a, http://links.lww.com/SHK/A595), so a difference cannot be obtained. Furthermore, the wide confidence intervals preclude characterizing a treatment effect. Variability is usually high in neuropsychological testing. We argue the tests are not sensitive enough to find a difference in these only mildly injured animals, and that our group sizes might have been too small for purposeful tests. For the tests of global activity and sensorimotor integration, which are often used and even have been developed for assessment in the setting of cardiac arrest (16), we might speculate that functional recovery have occurred since neuronal injury outside the CA1 region is very mild in our model (29).

As outlined before, we have seen mild neuronal injury compared to similar models of cardiac arrest. For example, Brücken's group used a 7 min cardiac arrest time, adding up the time to ROSC results in a combined no-flow/low-flow time of $645 \mathrm{sec}$ (30). Boettiger's group usually uses 6 minutes of $\mathrm{CA}$, and resuscitations takes about $160 \mathrm{sec}$, adding up to $520 \mathrm{sec}$ (16), which is less than our $650 \mathrm{sec}$ in the 10 minutes cardiac arrest groups. The postresuscitation care is similar to what is done by Brücken (ventilation for 4-5 hours), but early weaning from ventilation is usually done in Boettiger's experiments. Both groups use electrical currency to induce ventricular fibrillation, which might result in prolonged myocardial stunning and cardiac failure (31). This might explain the relatively low postresuscitation mortality in our experiments, which precluded survival analysis in series 1 . and resulted in a probably underpowered "false negative" result in survival analysis in series2. In our model, cardiac arrest is induced with potassium and esmolol, a short-acting $\beta$ receptor antagonist. Neuroprotective properties of beta-blocking substances have been discussed (32), but esmolol is relatively short-living and should not cross the blood-brain barrier. We think the neuropotective effect of esmolol is small, if ever, but we cannot exclude an effect. 
This is the first in-vivo study performed so far on pifithrin- $\mu$ administration in animals that underwent cardiac arrest and resuscitation. The main strength of our study is that we employed a reproducible cardiac arrest model, with standardized post-cardiac arrest conditions. A limitation of our study is the wide variability of the results, particularly in neurobehavioral tests. The significant reduction of the cell layer breadth of the CA1 segment in the pifithrin- $\mu$ group (table suppl. 4, http://links.lww.com/SHK/A595) must be interpreted cautiously because the borders of the CA1 segment is difficult to delineate in the u-shaped hippocampus and cannot be standardized by simple manners. We therefore decided to abstain from this examination in the second series.

The results in the CV staining did not reach statistical significance, which is unexpected, given the results of the Fluoro Jade B staining. We think this is due to two circumstances. First, determination of damage by cresyl violet staining, which is a non-specific stain, relies on purely morphological criteria (shrunken appearance and condensed nucleus) and is not firm, compared the easily identifiable degenerating neurons in the FJB staining. Second, since hippocampal damage after ischemic event is an evolving mechanism, assessment of neuronal damage with the $\mathrm{CV}$ staining based on morphological criteria is likely to detect cell death in a more advanced stage. In contrast, FluoroJade staining already labels damaged neurons with a rather intact morphology. Therefore results are likely to differ between both methods, depending on the time at which brains were harvested after the insult. Such differences between staining methods have been reported previously, although in different models $(33,34)$. The trend in the CV staining show in the same direction as the FJB staining, which supports our results.

The current literature exhibits insufficient knowledge of dose, timing, duration, and diluents of pifithrin- $\mu$. In our first series, we have administered $8 \mathrm{mg} / \mathrm{kg}$ of pifithrin- $\mu$ intraperitonally, which is based on the experiment of Nijboer et al. (10). Nijboer has used two different doses 
of pifithrin- $\mu$ ( 2 and $8 \mathrm{mg} / \mathrm{kg}$ ), the lower dose had no effect. To circumvent the insecurity of intraperitoneal drug administration, we have used an intravenous formulation in the second series. We have used a dose of $12 \mathrm{mg} / \mathrm{kg}$ of pifithrin- $\mu$ in ethanol (instead of DSMO) as a starting point, but did not see a dose effect. This has to be explored by further animal studies. Furthermore, the effect of pifithrin- $\mu$ on systemic inflammatory response is not yet known. In addition, since permanent damage or dysfunctional p53 invariably leads to cancer, and other untoward effects of temporary blockade of p53 might arise (e.g. adverse remodeling of myocardial infarct zone even though reduced myocyte apoptosis (26)) the long-term effects of temporary p53 inhibition needs be studied in the future.

\section{Conclusion}

After cardiac arrest and resuscitation, temporary inhibition of the neuronal apoptosis via the mitochondrial pathway with the small molecule pifithrin- $\mu$ reduces neuronal damage in the brain's most vulnerable area, the hippocampus CA1 region, compared to control. The optimal dose, route of administration, and long term effects of temporarily blocking apoptosis need to be studied further.

\section{List of abbreviations}

CA-1: Cornu Ammonis 1 segment of the hippocampus

CV: cresyl violet

DMSO: dimethylsulfoxide

FJB: Fluoro-Jade B

IQR: interquartile range 
PBS: phosphate buffered saline

ROSC: return of spontaneous circulation

\section{Declarations}

\section{Ethics approval and consent to participate}

This study compiled with the Swiss national guidelines for the Care and Use of Laboratory Animals, National Academy of Sciences,1996, and was performed with the approval of the Commission of Animal Experimentation of Canton Bern, Switzerland (BE 55/13 and BE $16 / 15)$

\section{Acknowledgement}

The experiments were conducted at the Experimental Surgery Unit of the Department of Clinical Research, University of Bern, we thank their personnel for their help. 
1. McNally B, Robb R, Mehta M, Vellano K, Valderrama AL, Yoon PW, Sasson C, Crouch A, Perez AB, Merritt R, et al.: Out-of-hospital cardiac arrest surveillance --Cardiac Arrest Registry to Enhance Survival (CARES), United States, October 1, 2005--December 31, 2010. MMWR Surveill Summ 60(8):1-19, 2011.

2. Mozaffarian D, Benjamin EJ, Go AS, Arnett DK, Blaha MJ, Cushman M, Das SR, de Ferranti S, Despres JP, Fullerton HJ, et al.: Executive Summary: Heart Disease and Stroke Statistics--2016 Update: A Report From the American Heart Association. Circulation 133(4):447-54, 2016.

3. Sanghavi P, Jena AB, Newhouse JP, Zaslavsky AM: Outcomes After Out-of-Hospital Cardiac Arrest Treated by Basic vs Advanced Life Support. JAMA Intern Med 175(2):196-204, 2015.

4. Daya MR, Schmicker RH, Zive DM, Rea TD, Nichol G, Buick JE, Brooks S, Christenson J, MacPhee R, Craig A, et al.: Out-of-hospital cardiac arrest survival improving over time: Results from the Resuscitation Outcomes Consortium (ROC). Resuscitation 91:108-15, 2015.

5. Hossmann KA: Cerebral ischemia: models, methods and outcomes. Neuropharmacology 55(3):257-70, 2008.

6. Vaseva AV, Moll UM: The mitochondrial p53 pathway. Biochim.Biophys.Acta 1787(5):414-420, 2009.

7. Elkholi R, Chipuk JE: How do I kill thee? Let me count the ways: p53 regulates PARP-1 dependent necrosis. Bioessays 36(1):46-51, 2014.

8. Lee JM, Bernstein A: p53 mutations increase resistance to ionizing radiation. Proc Natl Acad Sci U S A 90(12):5742-6, 1993.

9. Venna VR, Verma R, O'Keefe LM, Xu Y, Crapser J, Friedler B, McCullough LD: Inhibition of Mitochondrial P53 Abolishes the Detrimental Effects of Social Isolation on Ischemic Brain Injury. Stroke 45(10):3101-3104, 2014.

10. Nijboer CH, Heijnen CJ, van der Kooij MA, Zijlstra J, van Velthoven CT, Culmsee C, van $\mathrm{BF}$, Hagberg $\mathrm{H}$, Kavelaars A: Targeting the p53 pathway to protect the neonatal ischemic brain. Ann.Neurol. 70(2):255-264, 2011.

11. Cui D, Shang H, Zhang X, Jiang W, Jia X: Cardiac arrest triggers hippocampal neuronal death through autophagic and apoptotic pathways. Sci Rep 6:27642, 2016.

12. Frick T, Springe D, Grandgirard D, Leib SL, Haenggi M: An improved simple rat model for global cerebral ischaemia by induced cardiac arrest. Neurol Res:1-8, 2016.

13. Schmidt-Kastner R, Freund TF: Selective vulnerability of the hippocampus in brain ischemia. Neuroscience 40(3):599-636, 1991.

14. Katz L, Ebmeyer U, Safar P, Radovsky A, Neumar R: Outcome model of asphyxial cardiac arrest in rats. J Cereb.Blood Flow Metab 15(6):1032-1039, 1995.

15. Walsh RN, Cummins RA: The Open-Field Test: a critical review. Psychol Bull 83(3):482-504, 1976.

16. Albertsmeier M, Teschendorf P, Popp E, Galmbacher R, Vogel P, Bottiger BW: Evaluation of a tape removal test to assess neurological deficit after cardiac arrest in rats. Resuscitation 74(3):552-8, 2007.

17. Leib SL, Heimgartner C, Bifrare YD, Loeffler JM, Taauber MG: Dexamethasone aggravates hippocampal apoptosis and learning deficiency in pneumococcal meningitis in infant rats. Pediatr Res 54(3):353-7, 2003.

18. Foulkes WD: p53--master and commander. N Engl J Med 357(25):2539-41, 2007. 
19. Mondal S, Bhattacharya K, Mallick A, Sangwan R, Mandal C: Bak compensated for Bax in p53-null cells to release cytochrome $\mathrm{c}$ for the initiation of mitochondrial signaling during Withanolide D-induced apoptosis. PLoS One 7(3):e34277, 2012.

20. Vaseva AV, Marchenko ND, Ji K, Tsirka SE, Holzmann S, Moll UM: p53 opens the mitochondrial permeability transition pore to trigger necrosis. Cell 149(7):1536-48, 2012.

21. Vousden KH, Lu X: Live or let die: the cell's response to p53. Nat.Rev.Cancer 2(8):594-604, 2002.

22. Plesnila N, von BL, Retiounskaia M, Engel D, Ardeshiri A, Zimmermann R, Hoffmann F, Landshamer S, Wagner E, Culmsee C: Delayed neuronal death after brain trauma involves p53-dependent inhibition of NF-kappaB transcriptional activity. Cell Death.Differ. 14(8):1529-1541, 2007.

23. Strom E, Sathe S, Komarov PG, Chernova OB, Pavlovska I, Shyshynova I, Bosykh DA, Burdelya LG, Macklis RM, Skaliter R, et al.: Small-molecule inhibitor of p53 binding to mitochondria protects mice from gamma radiation. Nat.Chem.Biol. 2(9):474-479, 2006.

24. Komarov PG, Komarova EA, Kondratov RV, Christov-Tselkov K, Coon JS, Chernov MV, Gudkov AV: A chemical inhibitor of p53 that protects mice from the side effects of cancer therapy. Science 285(5434):1733-1737, 1999.

25. Culmsee C, Zhu X, Yu QS, Chan SL, Camandola S, Guo Z, Greig NH, Mattson MP: A synthetic inhibitor of $\mathrm{p} 53$ protects neurons against death induced by ischemic and excitotoxic insults, and amyloid beta-peptide. J Neurochem. 77(1):220-228, 2001.

26. Zhang Y, Kohler K, Xu J, Lu D, Braun T, Schlitt A, Buerke M, Muller-Werdan U, Werdan K, Ebelt H: Inhibition of p53 after acute myocardial infarction: reduction of apoptosis is counteracted by disturbed scar formation and cardiac rupture. $J$ Mol Cell Cardiol 50(3):471-8, 2011.

27. Yu W, Zhang X, Liu J, Wang X, Li S, Liu R, Liao N, Zhang T, Hai C: Cyclosporine A Suppressed Glucose Oxidase Induced P53 Mitochondrial Translocation and Hepatic Cell Apoptosis through Blocking Mitochondrial Permeability Transition. Int J Biol Sci 12(2):198-209, 2016.

28. Bendel S, Springe D, Pereira A, Grandgirard D, Leib S, Putzu A, Schlickeiser J, Jakob S, Takala J, Haenggi M: Do different anesthesia regimes affect hippocampal apoptosis and neurologic deficits in a rodent cardiac arrest model? BMC Anesthesiology 15(1):2, 2015.

29. Zuercher P, Springe D, Grandgirard D, Leib SL, Grossholz M, Jakob S, Takala J, Haenggi M: A randomized trial of the effects of the noble gases helium and argon on neuroprotection in a rodent cardiac arrest model. BMC Neurol 16(1):43, 2016.

30. Brucken A, Cizen A, Fera C, Meinhardt A, Weis J, Nolte K, Rossaint R, Pufe T, Marx G, Fries M: Argon reduces neurohistopathological damage and preserves functional recovery after cardiac arrest in rats. Br J Anaesth 110 Suppl 1:i106-12, 2013.

31. von Planta I, Weil MH, von Planta M, Bisera J, Bruno S, Gazmuri RJ, Rackow EC: Cardiopulmonary resuscitation in the rat. J Appl Physiol 65(6):2641-7, 1988.

32. Danura T, Takeda Y, Shiraishi K, Naito H, Mizoue R, Sato S, Morita K: Quantitative evaluation of the neuroprotective effects of a short-acting beta-adrenoceptor antagonist at a clinical dose on forebrain ischemia in gerbils: effects of esmolol on ischemic depolarization and histologic outcome of hippocampal CA1. J Neurosurg Anesthesiol 25(3):292-8, 2013.

33. Wang J, Jahn-Eimermacher A, Bruckner M, Werner C, Engelhard K, Thal SC: Comparison of different quantification methods to determine hippocampal damage after cerebral ischemia. J Neurosci Methods 240:67-76, 2015. 
34. Chaparro RE, Quiroga C, Bosco G, Erasso D, Rubini A, Mangar D, Parmagnani A, Camporesi EM: Hippocampal cellular loss after brief hypotension. Springerplus 2(1):23, 2013.

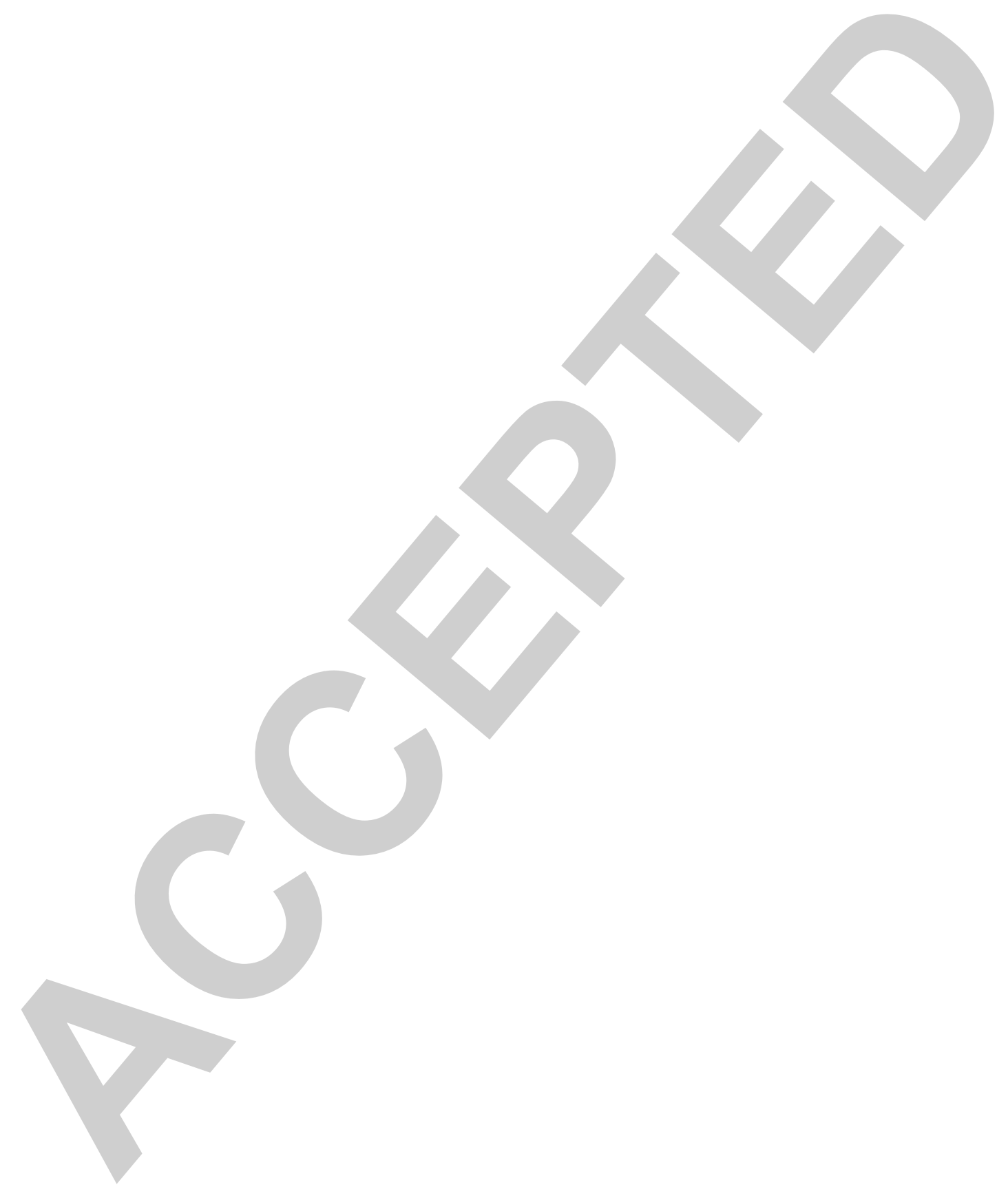




\section{Figure Legends}

Figure 1: Flow chart of the number of animals assigned into the different groups of series 1.6 animals were assigned to a sham group before randomization for laboratory standardization purposes and quality control. These animals were not analyzed. The remaining 74 rats were randomized before resuscitation to treatment group and to observation period $(1,5$ and $>10$ days).

$>10$ days refers to the animals which were tested in the watermaze after wound healing, starting the watermaze trial between day 10 and 14. Animals which could not be resuscitated were replaced immediately replaced with an animal from the same group and duration

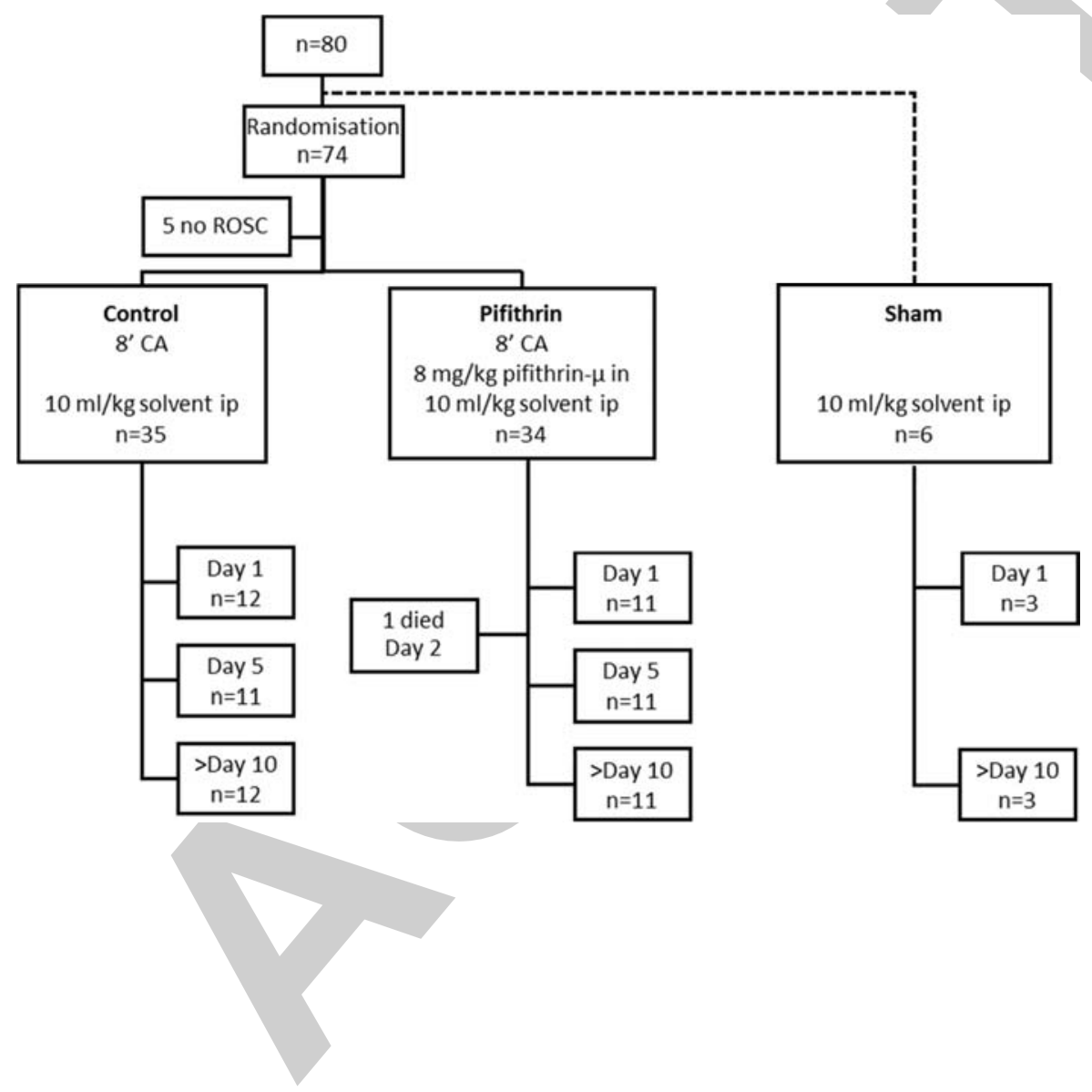


Figure 2: Left: Flow chart of the number of animals assigned into the different groups of series 2, Right: Survival analysis of the animals in series 2 .
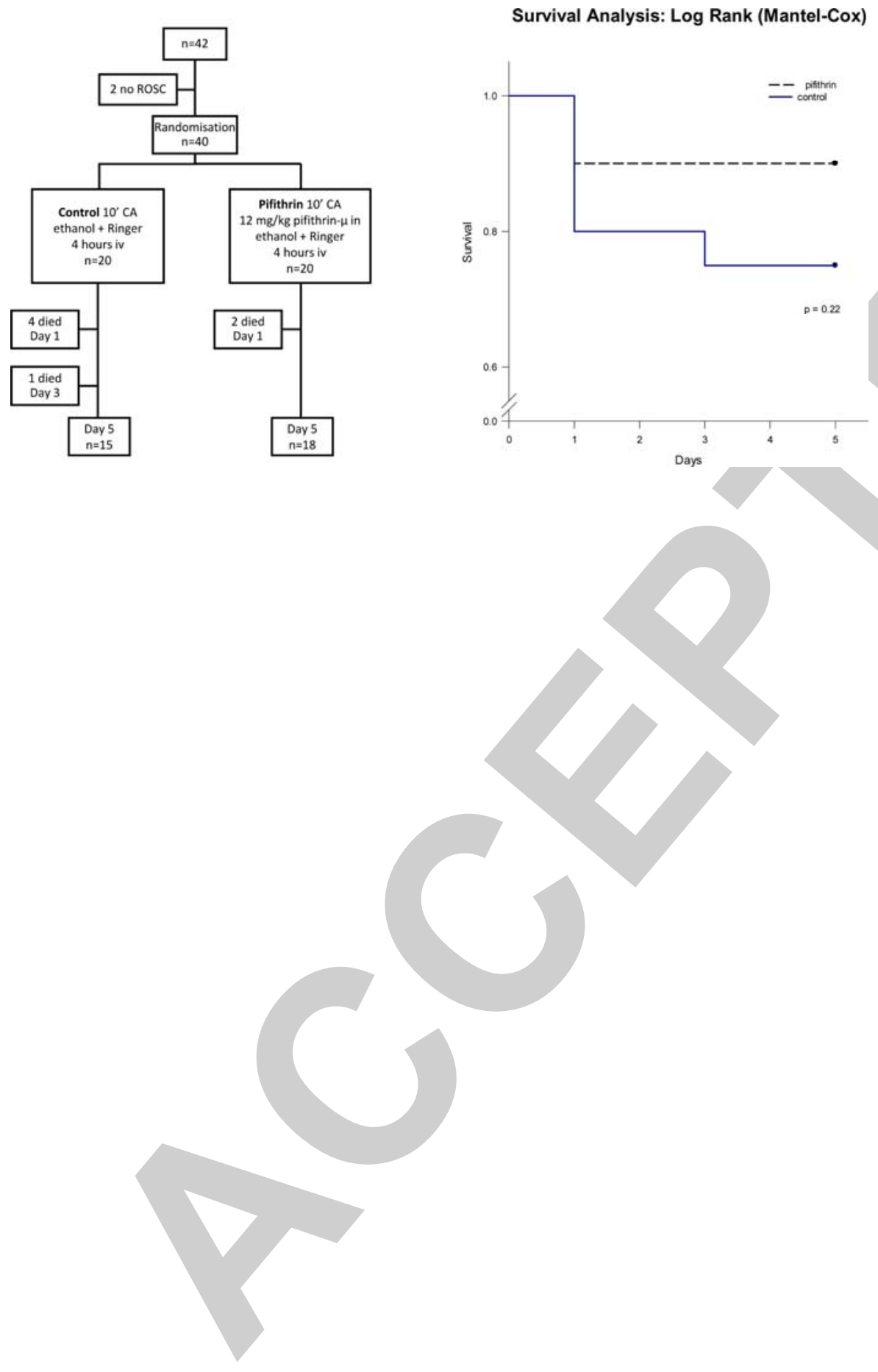
Figure 3: Representative pictures of the hippocampus where the green fluorescent neurons demonstrate degeneration. The right histological images (C and D) shows a cardiac arrest animal, contra to the left (A and B), which depicts a sham animal, which did not underwent cardiac arrest and resuscitation. Overview of the whole hippocampal structures (B and D) are provided, while higher magnification (A and $\mathrm{C}$ ) show degenerating neurons in the CA1 segment.
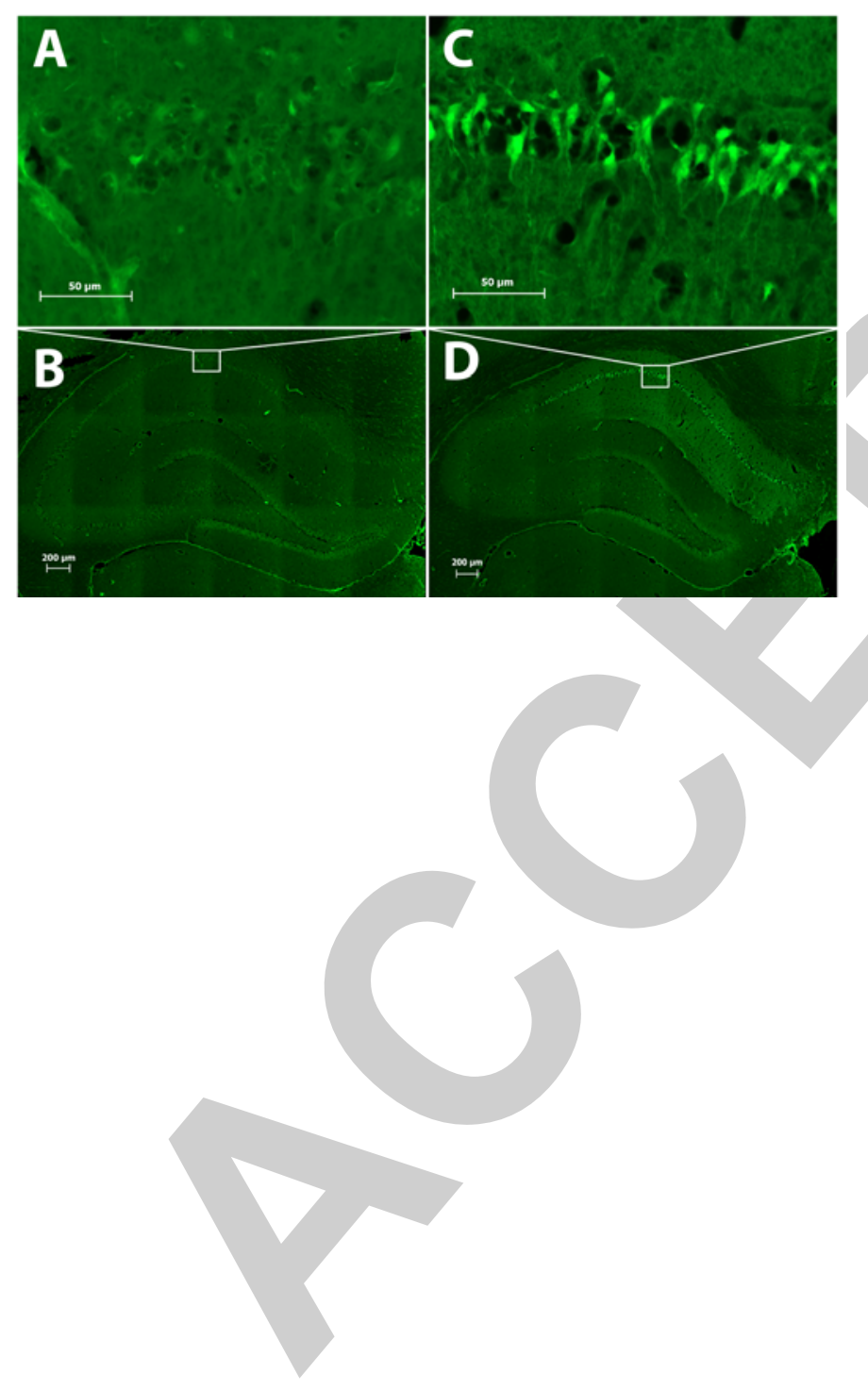


\section{Tables}

Table 1: Neuronal damage: histomorphometry of the hippocampus CA1 segment on day 5 with Fluoro-Jade

\begin{tabular}{|c|c|c|c|c|c|}
\hline variable & series & pifithrin & control & $\begin{array}{c}\text { post-hoc } \\
\text { t-test }\end{array}$ & ANOVA \\
\hline \multirow{2}{*}{$\begin{array}{l}\text { Fluoro-Jade } \\
\text { [numbers } \\
\text { of stained } \\
\text { cells } / \mathrm{mm} \text { ] }\end{array}$} & $\begin{array}{l}\text { Series } 1 . \\
\text { [8 min } \\
\text { cardiac } \\
\text { arrest }]\end{array}$ & $94 \pm 46.9$ & $128 \pm 36.6$ & $\mathrm{p}: 0.084$ & \multirow{2}{*}{$\begin{array}{c}\text { p group: } 0.014 \\
\text { p exp.: } 0.064 \\
\text { p group x exp: } \\
0.622\end{array}$} \\
\hline & $\begin{array}{c}\text { Series } 2 . \\
{[10 \mathrm{~min}} \\
\text { cardiac arrest }\end{array}$ & $78 \pm 43.7$ & $101 \pm 31.0$ & & \\
\hline \multirow{2}{*}{$\begin{array}{c}\text { Fluoro-Jade } \\
{[\text { normalized to }} \\
\text { control }=100 \%]\end{array}$} & $\begin{array}{l}\text { Series } 1 . \\
{[8 \text { min }} \\
\text { cardiac } \\
\text { arrest }]\end{array}$ & $73 \pm 36.6$ & $100 \pm 28.5$ & p: 0.084 & \multirow{2}{*}{$\begin{array}{c}\text { p group: } 0.019 \\
\text { p exp.: } 0.850 \\
\text { p group x exp: } \\
0.850\end{array}$} \\
\hline & $\begin{array}{l}\text { Series .2 } \\
{[10 \text { min }} \\
\text { cardiac } \\
\text { arrest }]\end{array}$ & $77 \pm 43.3$ & $100 \pm 31.7$ & p: 0.095 & \\
\hline
\end{tabular}

Fluoro Jade is a marker for degenerating neurons. The stained CA1 segment of the rat's hippocampus were examined and results are given in absolute cell counts per mm CA1 (top), and as percentage in relation to the control group ( $=100 \%$, bottom). (numbers are mean \pm standard deviation) 
Table 2: Neuronal damage: histomorphometry of the hippocampus CA1 segment on day 5 with Cresy Violett

\begin{tabular}{|c|c|c|c|c|c|}
\hline variable & Serie & pifithrin & control & $\begin{array}{c}\text { post-hoc } \\
\text { t-test }\end{array}$ & ANOVA \\
\hline \multirow{2}{*}{$\begin{array}{c}\text { pyknotic cells in } \\
\text { CA1 }[\%]\end{array}$} & $\begin{array}{c}\text { Series 1. } \\
{[8 \mathrm{~min}} \\
\text { cardiac } \\
\text { arrest }]\end{array}$ & $25 \pm 16.7$ & $39 \pm 21.4$ & p: 0.111 & \multirow{2}{*}{$\begin{array}{c}\text { p group: } 0.118 \\
\text { p exp.: } 0.039 \\
\text { p group x exp.: } \\
0.830\end{array}$} \\
\hline & $\begin{array}{l}\text { Series 2. } \\
{[10 \mathrm{~min}} \\
\text { cardiac } \\
\text { arrest }]\end{array}$ & $43 \pm 28.8$ & $53 \pm 26.3$ & p: 0.321 & \\
\hline \multirow{2}{*}{$\begin{array}{l}\text { pyknotic cells } \\
\text { [normalized to } \\
\text { control }=100 \%]\end{array}$} & $\begin{array}{c}\text { Series } 1 . \\
{[8 \mathrm{~min}} \\
\text { cardiac } \\
\text { arrest }]\end{array}$ & $65 \pm 43.3$ & $100 \pm 55.5$ & & \multirow{2}{*}{$\begin{array}{c}\text { p group: } 0.063 \\
\text { p exp.: } 0.552 \\
\text { p group x time: } \\
0.552\end{array}$} \\
\hline & $\begin{array}{l}\text { Series } 2 . \\
{[10 \text { min }} \\
\text { cardiac } \\
\text { arrest }]\end{array}$ & $81 \pm 54.3$ & $100 \pm 49.5$ & p: 0.321 & \\
\hline
\end{tabular}

Pyknotic appearing cells determine apoptosis. The stained CA1 segment of the rat's hippocampus were examined and results are given in absolute cell counts per mm CA1 (top), and as percentage in relation to the control group $(=100 \%$, bottom) (numbers are mean \pm standard deviation) 